\title{
ENSINO E CULTURA POPULAR: CAMINHOS PARA A CONSTRUÇÃO DE SABERES SOCIOHISTÓRICOS EM AÇAILÂNDIA-MA
}

\author{
Marcelo de Jesus de Oliveira ${ }^{1}$ \\ https://orcid.org/0000-0003-0981-2737
}

RESUMO: Este artigo apresenta reflexões histórico-sociais ao discutir as significações de cultura popular e sua relevância na produção de conhecimento popular de alunos dos anos finais do ensino fundamental, em uma escola pública situada na zona rural de Açailândia, município do estado do Maranhão. Objetivou-se, portanto, a partir das reflexões oportunizadas pelo público participante, compreender a produção de conhecimento social utilizando a cultura popular dos indivíduos envolvidos no processo. Para tanto, utiliza-se embasamentos teórico-metodológicos da corrente de pensamento construtivista de Jean Piaget (1896-1930) e socioconstrutivista de Lev Vygotsky (1896-1934), bem como conceitos e ideias Paulo Freire (1996); José Cruz (2008); Petrônio Domingues (2011); Vera Werneck (2006); Roque Laraia (1986), dentre outros. Como resultado final desta pesquisa, obtém-se a contextualização discursiva da possibilidade de uso da cultura popular como construtora do saber de mundo e didático dos indivíduos, uma vez que o homem é submetido à experiência coletiva e, enquanto ser social, comunga de costumes de dissidentes grupos de indivíduos, tais que influenciam no modo de recepção e construção do conhecimento humano.

PALAVRAS-CHAVE: Ensino, cultura popular, produção de conhecimento.

\section{EDUCATION AND POPULAR CULTURE: PATHS FOR THE CONSTRUCTION OF SOCIO-HISTORICAL KNOWLEDGE IN AÇAILÂNDIA-MA}

ABSTRACT: This article presents historical and social reflections when discussing the meanings of popular culture and its relevance in the production of popular knowledge of students in the final years of elementary school, in a public school located in the rural area of Açailândia, municipality of the state of Maranhão. It was aimed, therefore, from the reflections provided by the participating public, to understand the production of social knowledge using the popular culture of the individuals involved in the process. To do so, we used the theoretical and methodological foundations of Jean Piaget's (1896-1930) constructivist current of thought and Lev Vygotsky's (1896-1934) socioconstructivist current of thought, as well as concepts and ideas from Paulo Freire

1 Mestre em Letras - Literatura, História e Imaginário (UFT). Açailândia Maranhão. Brasil. pfmarcelopt@ gmail.com

Rev. Fac. Educ. (Univ. do Estado de Mato Grosso), Vol. 35, Ano 20, № 1, p. 231-248, jan/jun, 2021. 
(1996); José Cruz (2008); Petrônio Domingues (2011); Vera Werneck (2006); Roque Laraia (1986), among others. As a final result of this research, we obtain the discursive contextualization of the possibility of using popular culture as a builder of world and didactic knowledge of individuals, since man is subjected to the collective experience and, as a social being, shares the customs of dissenting groups of individuals, such that influence the mode of reception and construction of human knowledge.

KEY WORDS: Teaching, popular culture, knowledge production.

\section{EDUCACIÓN Y CULTURA POPULAR: CAMINOS PARA LA CONSTRUCCIÓN DEL CONOCIMIENTO SOCIO-HISTÓRICO EN AÇAILÂNDIA-MA}

RESUMEN: Este artículo presenta reflexiones históricas y sociales al discutir los significados de la cultura popular y su relevancia en la producción de conocimiento popular de los alumnos de los últimos años de la escuela primaria, en una escuela pública ubicada en la zona rural de Açailândia, municipio del estado de Maranhão. Se pretendía, por tanto, a partir de las reflexiones aportadas por el público participante, comprender la producción de conocimiento social utilizando la cultura popular de los individuos implicados en el proceso. Para ello, utilizamos fundamentos teóricos y metodológicos de la corriente de pensamiento constructivista de Jean Piaget (18961930) y del constructivista social Lev Vygotsky (1896-1934), así como conceptos e ideas Paulo Freire (1996); José Cruz (2008); Petrônio Domingues (2011); Vera Werneck (2006); Roque Laraia (1986), entre otros. Como resultado final de esta investigación, se obtiene la contextualización discursiva de la posibilidad de utilizar la cultura popular como constructora de mundo y conocimiento didáctico de los individuos, ya que el hombre está sometido a la experiencia colectiva y, como ser social, comparte costumbres de grupos de individuos disidentes, tales que influyen en el modo de recepción y construcción del conocimiento humano.

PALABRAS CLAVE: Enseñanza, cultura popular, producción de conocimiento.

\section{Introdução}

A educação brasileira, ainda na contemporaneidade, esbarra-se em severos problemas políticos e didáticos. Em todos os níveis e componentes curriculares percebe-se uma escassez de propostas eficazes e inovadoras que visem promover o ensino didático, lúdico e proveitoso, como assim assegu- 
ra a Constituição Federal de 1988 e outros mais documentos e orientações educacionais. Observa-se, ainda, que parcelas significativas dos profissionais da educação desconsideram, frequentemente, perspectivas educacionais requisitadas por entidades normalizadoras do sistema do ensino público, por exemplo, a dialogicidade do ensino em consonância com a realidade dos indivíduos inseridos neste processo, isto é, as tendências e emblemáticas trabalhadas em salas de aulas pautadas nas dependências da Lei de Diretrizes e Base da Educação - LDB.

As interações entre conhecimento didático e a vivência social e prática são exigidas por estes documentos em observância ao processo de expansão cognitiva, já que este acontece por canais mentais que estão aliados aos comportamentos humanos. Em outras palavras, o modo pelo qual o indivíduo concebe e assimila conhecimentos está intrinsecamente ligado ao meio social e cultural em que é imerso. Sendo assim, faz-se necessário que anteceda o processo de teorização por conteúdo, análises pragmáticas dos costumes sociais que transcendem a temática abordada em aula, para que o alunado possa sentir-se membro efetivo daquela comunidade, bem como participar das aulas com maior propriedade.

Pensando nisso, este estudo buscou compreender a produção do conhecimento social e didático utilizando as reflexões sobre cultura popular dos alunos dos anos finais do ensino fundamental de uma escola na zona rural de Açailândia-MA. Para tanto, além de pesquisas de cunho bibliográfico e natureza qualitativa, foram analisados dados construídos a partir da aplicação de um questionário com o público participante, compostos por alunos dos oitavos e nonos anos, turmas $\left(8^{\mathrm{a}}, 8^{\mathrm{b}}, 8^{\mathrm{c}}, 9^{\mathrm{a}}\right.$ e $\left.9^{\mathrm{b}}\right)$, que se voluntariaram após a apresentação inicial da pesquisa. Por conseguinte, os dados foram transcritos, tabulados e analisados com auxílio do software Microsoft Word 2016.

Por tratar-se de discussões que atravessam o processo de aquisição e construção do conhecimento humano, teorias advindas da corrente de pensamento construtivista de Jean Piaget (1896-1930) e socioconstrutivista de Vygotsky (1896-1934), foram utilizadas para embasamento e discussão dos dados apresentados, pois fez-se necessário compreender o modelo de processamento do mecanismo de ensino-aprendizagem, além do sistema de assimilação, acomodação e expansão do conhecimento adquirido.

As observações realizadas em sala de aula durante a etapa em campo desta pesquisa, assim como o exercício do ofício docente do pesquisador envolvido, apontam para uma discussão pertinente - a dificuldade dos docentes em unir cultura popular aos conteúdos didáticos explorados em sala de aula 
- assim, auxiliando a definição efetiva do problema desta pesquisa, sendo ele: É possível conceber a cultura popular dos indivíduos como proposta didática, inovadora e eficaz para o ensino público?

Assim, este trabalho está estruturado em duas dissidentes abordagens: na primeira, são apresentados os dados extraídos da abordagem bibliográfica, sobretudo as correlações da concepção dos autores selecionados para compor o aporte teórico deste estudo às análises interpretativas e reflexivas do pesquisador; na segunda, discute-se os dados obtidos pela aplicação dos questionários durante a abordagem in loco.

Contudo, é válido salientar que este trabalho não detém como objetivo central elencar propostas e métodos absolutos de como ou quando se deve trabalhar com cultura popular no exercício do ofício docente, visto que as escolas e todos os membros que as compõem são passíveis da autonomia de criar, recriar e adaptar formas de ensino. Assim, as proposições trazidas neste trabalho devem ser recebidas como configurações possíveis de união dos ecos da cultura popular em consonância com as práticas educativas, sem distinção de quaisquer níveis ou disciplinas.

\section{Considerações sobre a construção e assimilação do ensino}

No processo de desenvolvimento cognitivo e físico do ser humano o indivíduo está sujeito a constantes modificações em sua estrutura, principalmente no âmbito cerebral/cognitivo, haja vista que são nestas estruturas onde nascem e desenvolvem, mecanicamente, as alterações incipientes e inerentes às habilidades a serem desenvolvidas. A absorção do conhecimento, majoritariamente na fase inicial, ainda quando o indivíduo não detém domínio considerável sobre suas ações, surge da relação do sujeito com o mundo e a partir daí se desenvolvem.

A partir desta ocorrência a vivência influencia diretamente o desenvolvimento do indivíduo que passará por outras configurações de construção e assimilação do conhecimento, tornando-se, desse modo, protagonista da referida ação. Pois, "o homem transforma a natureza tanto por sua ação individual quanto social num mundo de cultura que vai para ele aparecer revestido de valor" (WERNECK, 2016, p. 177). Desse modo, cada indivíduo compreende sua cultura como patrimônio de uma sociedade que foi historicamente criada, isto é, o meio social o qual o cidadão está inserido é incumbido grandemente pela formação cultural e social deste sujeito.

Além disso, considera-se pertinente ressaltar que a noção de constru- 
ção de conhecimento ultrapassa a questão da unilateralidade semântica, pois pode haver sentidos e significações diversas. À guisa de definição, Werneck (2016) considera construção "o ato de construir algo, e, como ato ou ação a terceira fase do processo é à (sic) vontade" (WERNECK, 2016, p. 175). Dessa maneira, consoante à linha de raciocínio da autora, toda construção é produto de um processo no qual três procedimentos são realizados simultaneamente: deliberação, decisão e excussão.

Por ser assim, compreende-se que o processo de construção é uma ação entendida como racional, visto que quando posto em excursão dos três princípios fundamentais - elencados anteriormente - a produção fica, então, condicionada a inteligência e vontade do indivíduo. Sendo assim, não se pode descrer da interação do sujeito com o meio em que vive, haja vista que ambos estão intrinsecamente ligados em perspectivas de adesão ao conhecimento humano. Assim, para que haja esta relação, é necessário, também, que se desenvolvam outras situações de assimilação do objeto conhecido, tais que justificam, de forma sistemática, os casos e meios de acomodação destes.

O conhecimento, ainda baseado na abordagem de relação entre sujeito e ambiente, dá-se, também, por diferentes meios, e, consequentemente, abrem margens para o surgimento de novos tipos de saberes, tais como; o empírico que consiste nas experiências diárias do indivíduo; o saber filosófico, que tem como principal característica as condições corriqueiras do dia a dia e outros.

Tem-se ainda o saber teológico, que tem com ocupação os estudos referentes às divindades e a relação dos deuses e os homens e, também, o saber científico, aquele que precisa obrigatoriamente ser provado pela ciência, ou ainda, o conhecimento que é advindo da dúvida e concretizado por respostas absolutas (GERHARDT \& SILVEIRA, 2009).

A discussão em torno da própria expressão de conhecimentos e suas formas de adesão, por sua vez, principia calorosas discussões envolvendo grandes nomes da filosofia clássica, como Sócrates e Platão. Elucida-se que tanto a filosofia clássica como a contemporânea sempre estiveram envolvidas com os processos de alicerce do conhecimento, sobretudo filosófico. Na obra Teeteto Crálito (2001), de Platão, por exemplo, o pensador afirma que o "conhecimento não pode ser nem sensação, nem opinião verdadeira, nem a explicação racional acrescentada a essa opinião" (PLATÃO, 2001, p. 76).

Nesta ótica, o filósofo acredita que o conhecimento não pode ser considerado uma sensação, tampouco uma opinião verdadeira ou explicação racional, pois ultrapassa os limites delimitados nesta perspectiva, assim, re- 
jeitando as condições prescritas para definição do vocábulo em questão, pois defende que é necessário conhecimento para ser qualificado como tal.

Por outro lado, em paralelo ao pensamento platônico, diante dos emblemas da construção do conhecimento e sua definição, destaca-se as concepções de Sócrates. As atribuições do referido pensador em relação a tal discussão demonstram um intenso interesse pela comprovação que a sabedoria era limitada pela sua própria arrogância, e que os erros eram consequência da ignorância humana.

Assim, propunha como modelo de aprendizagem a maiêutica, que consiste em uma sequência de interrogações acerca de um determinado conteúdo, que tinha como objetivo avaliar a profundidade do conhecimento do indivíduo e, também, levar as pessoas a conhecer seus preceitos desconhecidos. Sendo assim, não diferente dos demais pensadores que discorrem sobre a construção do saber, Sócrates também nutria a compreensão que o indivíduo e o meio estão diretamente ligados neste processo.

\section{O processo de ensino aprendizagem}

As reflexões realizadas acerca das práticas pedagógicas exercidas no ensino público brasileiro permitem constatar séries de influências de diferentes correntes teóricas no âmbito do processo de ensino-aprendizagem (GOLDEM$B E R G, 1993)$. Os mecanismos de ensino e aprendizagem têm espaço direto no ambiente de ensino, influenciando os apontamentos educativos, pois, é neste processo que se centra a atenção social, ou seja, em todos os envolvidos e os aspectos que os compreendem.

É de tamanha complexidade discutir processo de ensino-aprendizagem no contexto educacional público brasileiro, uma vez que, quando polemizado, a unanimidade define como principal atraso da educação: a supervalorização da prática de memorização dentro das salas de aulas. Esta ocorrência, por sua vez, dificulta consideravelmente a prática e o desenvolvimento do senso crítico dos indivíduos. Além do mais, o fato das ações educativas serem exclusivamente centradas no professor reflete negativo e diretamente no desavanço da educação brasileira, haja vista que o determina com ser superior, atingindo, consequentemente, a arbitrariedade de definir o que é e como será aprendido/ ensinado (GOLDEMBERG, 1993).

Neste contexto, é cabível pautar, ainda, que no sistema de educação contemporâneo "o espaço de saber do docente foi dando lugar ao de mediador e problematizador do aprender: ele passou a ser visto como aquele que desafia 
os alunos, mostrando-lhes, entre as várias possibilidades de aprendizagem, caminhos que poderão ser percorridos" (CRUZ, 2008, p. 1072). Esta nova postura, por sua vez, permite a fluidez e um ensino significativamente mais justo e confortável para ambas as partes envolvidas no processo.

Além do mais, situar o professor como ponto central do processo de ensino-aprendizagem acarretam vastas mazelas ao sistema, visto que "aproveitar o potencial que o indivíduo traz e valorizar a curiosidade natural da criança são princípios que devem ser observados pelo educador" (BRUNER, 1991, p. 122). Sendo assim, o mediador deve atentar-se a explorar as propriedades intelectuais dos alunos, desenvolvendo atividades que estejam inteiramente ligadas ao seu cotidiano, pois é de extrema necessidade que o indivíduo não se sinta deslocado das propostas abordadas em sala de aula e que, mais que isso, estejam preparados para contribuir ativamente com atividades propostas, pois desenvolve o interesse e a vontade de estar sendo representado por si só no ambiente escolar, enfatizando consequentemente, o quão valorosa é sua participação na sociedade como agente ágil e dinâmico.

A educação deve acontecer de forma que torne o indivíduo um cidadão autônomo e crítico, por isso, a equipe docente e a instituição família devem ser incumbidas de criar subsídio que beneficie e despertem o pensamento crítico fazendo, assim, acontecer o processo de construção do conhecimento, haja vista que "ensinar não é transferir conhecimento, mas criar as possibilidades para a sua produção ou a sua construção" (FREIRE, 1996, p. 25).

Sendo assim, visto que o indivíduo em formação está sujeito a transformações inerentes ao meio que vive, faz-se necessário assimilar que o processo de ensino-aprendizagem pode ser compreendido e caracterizado por diferentes formas, tendo estas formas teorias e estudiosos como representantes. Privilegiou-se, nesta pesquisa, as teorias de Jean Piaget (1896-1930) e Vygotsky (1896-1934), correlacionando-as de modo que esclareça a relação dos estudos da cultura, escola e construção do conhecimento humano.

\section{Encontros e dissidências - Piaget e Vigotsky}

Vygotsky atribui uma grande significância ao processo de ensino-aprendizagem com a sua teoria de desenvolvimento e aprendizagem. $\mathrm{O}$ autor, em suas obras, dá espaço de destaque à ideia de que a criança inicia sua postura de aprendiz antes mesmo de iniciar o percurso escolar e, posteriormente, este percurso desenvolverá novos atributos em seu desenvolvimento (VIGOTSKY, 2003). Sendo assim, o desenvolvimento e a aprendizagem estão 
inter-relacionados desde o momento do nascimento, o meio físico ou social influencia no aprendizado das crianças de modo que chegam às escolas com uma série de conhecimentos adquiridos" (COELHO \& PISONI. 2012, p. 149). Assim, na perspectiva de Vygotsky, o indivíduo possui duas formas de adesão do conhecimento; os conceitos cotidianos, que são adquiridos com o tempo no decurso da vida e, também, os conceitos científicos representados pelos conhecimentos advindos da sala de aula e que devem relacionar-se, diretamente, com o conhecimento de mundo.

Piaget e Vygotsky possuem pontos semelhantes no que diz respeito a suas teorias, sobretudo no princípio fundamental delas, pois, Piaget também defende que "o indivíduo se desenvolve a partir da ação sobre o meio em que está inserido, priorizando, a princípio, os fatores biológicos que podem influenciar seu desenvolvimento mental" (OLIVEIRA. et al. 2018). Dessa forma, esta reflexão evidencia que ambos os pensadores são adeptos à relação do indivíduo com meio social o qual pertence.

Ademais, apresenta-se como característica primordial da teoria piagetiana os fatos das contribuições dispostas pelo pensador em seus estudos terem influenciado positivamente o processo de ensino-aprendizagem, fundamentando o aparecimento das inovações, transformações no mecanismo e desenvolvimento psicológico (PIAGET, 1977).

\section{Ensino e cultura popular}

A cultura popular é parte fundamental e íntima do cotidiano dos indivíduos, independentemente de gênero, raça ou idade. Por ser assim, é aceitável dizer que não há possibilidade de existência de um homem no mundo que não possua influência ou uma demonstração cultural predominante, sobretudo porque o meio no qual estamos inseridos exerce consideráveis influências sob nossas ações. Diante da discussão acerca da influência dos costumes culturais no convívio cotidiano do homem evidencia-se, então, a necessidade de conceitualização do termo e, por conseguinte, uma analogia de como a cultura popular relaciona-se com o homem contemporâneo.

A noção de cultura popular é um conceito relativamente moderno², uma vez que surge em meados do século XIX quando começam dividir os grupos sociais por classes e, consequentemente, dissociaram cultura popular e

2 A modernidade na qual nos referimos aqui se trata da conceitualização da expressão "cultura", ou ainda, "cultura popular", pois temos ciência que as culturas, propriamente ditas, sempre existiram desde o curso inicial da vida humana. 
cultura de elite (RIBEIRO, 2009). Para Azevedo (2008, p. 03) "A cultura popular é diversificada, heterogênea e heterodoxa e apresenta as mais variadas facetas e graduações nas diferentes regiões do país. Pode-se dizer que sua produção costuma ser expressão de cada contexto onde se desenvolve". Neste contexto, o autor pontua a diversidade de produção e expressão no âmbito da cultura popular e, por ser assim, melhor seria tratá-la no plural: culturas populares (AZEVEDO, 2008 \& DOMINGUES, 2011).

Para Turner (2018, p.46) o termo cultura é "um sistema de símbolos que uma população cria e usa para organizar-se, facilitar a interação e para regular o pensamento". Assim, embora os sistemas e símbolos auxiliem na organização sistemática de uma sociedade, como bem pontua o autor, as culturas populares existem para demonstrar suas verdades e histórias que são identificadas pelas identidades culturais.

Sendo assim, é imprescindível que se tenha cuidado na abordagem deste tema, pois não se trata somente de um único objeto de discurso, e sim de vários, que, por sua vez, manifestam-se nas esferas da sociedade de diversas formas. Neste trabalho, o conceito de cultura popular será tratado de forma ampla, fazendo breves recortes acerca da memória e identidade, pois "cultura popular e educação podem adquirir significados muito diferentes, dependendo do contexto ou da sociedade a partir da qual forem passadas" (SILVA, 2008, p. 07).

A cultura popular é, antes de tudo, a forma em que uma sociedade se estrutura em caráter de organização social, discursos, costumes, crenças, política ou clero e, por ser assim, é incumbida da configuração da história de um povo/nação. No entanto, quando posto em discussão a cultura no espaço escolar é necessário que se leve em consideração o fato da sociedade brasileira ser marcada por série de hierarquias, tais que levam sempre a associação de "cultura" à sofisticação; luxo; erudição ou, até mesmo, à educação elitizada. Diante disso, é necessário perceber estas discrepâncias conceituais para que possamos, por definitivo, desconstruir este pensamento de base elitista e, por conseguinte, propor a cultura popular como artifício eficiente, lúdico e acessível de ensino.

Em Açailândia-MA as instituições públicas de ensino já se atentaram, ainda que timidamente, para a prática docente sob a perspectiva de cultura popular. Na escola Darcy Ribeiro, por exemplo, são promovidos, anualmente, dois ou mais eventos específicos para trabalhar conteúdos referentes à cultura popular. Estes projetos são fomentados pela equipe técnica da Secretaria de Educação de Açailândia e distribuídos em todas as instituições de ensino mu- 
nicipais para serem executados nas dependências da escola ou locais públicos para que toda a comunidade tenha acesso.

Os projetos têm como objetivo desenvolver trabalhos referentes às culturas populares no ensino base das escolas públicas de Açailândia-MA e existem para formar leitores questionadores, capazes de acionar processos que motivem o interesse pela leitura e produção de textos, conforme à vice-diretora da escola-campo:

Esta instituição sempre promoveu eventos de cunho cultural desde sua fundação, sempre teve momentos culturais na escola e o resultado é a aprendizagem dos alunos que desenvolvem habilidade com leitura e escrita produzindo textos, panfletos, recontos e paródias sobre o folclore em geral ${ }^{3}$.

Além do mais, nota-se também que é resultado desse processo a maturação de ideias e pensamentos referente ao não habitual o que torna, consequentemente, esses indivíduos mais tolerantes frente às diversidades, bem como a intensificação da necessidade do respeito para com o próximo e, também, desenvolvendo com proficiência os desafios propostos em sala de aula. Diante disso, salienta-se que o ensino baseado nas perspectivas da cultura popular desempenha papel fundamental no que diz respeito ao percurso, ainda distante, da objetivação da educação libertadora.

Para Laraia (1986, p. 46) "cultura é um sistema de conhecimento que consiste em tudo aquilo que alguém tem de conhecer ou acreditar para operar de maneira aceitável dentro de sua sociedade". Sendo assim, não deixa de ser papel da escola abordar em sala de aula ou na comunidade conteúdos que compactuam ativamente no desenvolvimento social do indivíduo. É no espaço escolar que o cidadão se percebe enquanto membro ativo de um determinado grupo social e que, por isso, faz-se necessário compreender as especificidades que foram historicamente criadas.

A iniciativa em discorrer sobre cultura popular no locus desta pesquisa desenvolveu evoluções significativas no modo de pensar dos indivíduos passíveis deste processo que, durante a abordagem exploratória, mostraram-se possuir conhecimentos consistentes sobre o assunto discutindo, percebendo-se, então, através dos dados obtidos e processados na tabela 1.

3 Informação oral concedida por meio de uma entrevista semiestruturada sob consenso da profissional que, por motivos pessoais, optou por ter seu nome isento nessa pesquisa. 
Tabela 1 - Conceitualização de "cultura popular" dos entrevistados

Entrevistados/Ano

Conceito

8a A - Entrevistado (a)

"Cultura popular é algo que todos de uma mesma sociedade cultuam; que todos conhecem e levam consigo".

8 B - Entrevistado (a)

"É a cultura (forma de vida e hábitos) que cada povo tem".

8a C - Entrevistado (a) "É a memória de um povo".

9a A - Entrevistado (a) "Cultura popular pra mim são as tradições, as comidas típicas, os modos de falar, a história do povo, as lendas regionais e o próprio povo".

9a B - Entrevistado (a) "Costume comum de um povo como religião, arte e, principalmente, o respeito às diferenças".

Fonte: Tabela criada para fins da pesquisa (2019).

As falas acima apresentadas revelam a percepção dos entrevistados acerca da existência da pluralidade cultural que é pontuada por Azevedo (2008) e Domingues (2011), isto é, os discentes são capazes de perceber que cultura popular é parte intrínseca da interação social do indivíduo. Além do mais, percebem, ainda, a necessidade de se trabalhar com "culturas populares", pois, suas concepções permitem entender que não existe uma unidade e sim, várias culturas, como bem é colocado pelo (a) entrevistado (a) representante do nono ano b (9B). Além disso, é válido salientar a ênfase que deram ao "respeito ao próximo", que é representado em cada fala de maneira peculiar. Assim, compreende-se que estes projetos têm conferido desenvolvimento cognitivo a estes alunos que ultrapassam os conhecimentos didáticos e abarcam lições morais e éticas que subsidiarão um convívio social saudável nas dependências do espaço escolar e da vida.

Ademais, as mazelas marcadas no histórico social brasileiro são, acima de tudo, motivos suficientes para se dê devida atenção a esta temática; a repreensão, a desigualdade de gênero, raça, classe e outras mais atrocidades as quais foram e são submetidos estes povos, são elementos fundamentais no exercício do ensinar no viés da cultura popular. Este artifício pode subsidiar a construção de uma sociedade igualitária, disposta a fazer acontecer democracia que tanto é almejada - não somente no Brasil - além de tornar capaz de despertar as escolas a atentar-se aos antepassados, haja vista que muito 
tem a ver com cultura popular, ensino e educação.

Além de voltar os métodos de ensino para a cultura popular e, consequentemente, para os fatos do passado, pois estes se constituem também como memória cultural, é importante frisar a relevância que se é atribuída à memória no processo de ensino-aprendizagem, sendo assim, Silva (2008, p. 85) pontua que "falar de memória é, antes de tudo, falar de uma faculdade humana. A faculdade de conservar estados de consciência pretérita e tudo o que está relacionado a eles. A faculdade da memória é responsável por nossas lembranças". Nessa esteira, vale elencar que toda memória humana é substrato da existência de alguém e, portanto, falar de lembranças nada mais é que falar de quem lembra, considerando que quem efetivamente recorda são os indivíduos (SILVA, 2008).

Sendo assim, consideramos que no processo de se lembrar e ser lembrado há uma forte atuação do "eu" do próprio indivíduo, ao ponto de vista que a pessoa constrói sobre si mesma e, por fim, da pessoa que efetivamente é recordada. Pois, existem as memórias coletivas e individuais e ambas são de fundamental relevância no mecanismo de ensinar pela cultura popular, haja vista que ambas as teorias da construção do conhecimento concebem como pilar principal a relação do indivíduo com o meio em que vive.

Assim, ao tratar-se da nação brasileira percebe-se que muitas são as culturas populares vivenciadas pelos povos, assim, faz-se necessário está em constante busca por conhecimentos referentes à cultura popular, visto que pode ser compreendida como uma fonte inesgotável. Nesta perspectiva, os voluntários, durante as entrevistas, demonstraram serem relevantes aos estudos culturais nos mais diversos níveis de ensino, pois permite compreender as marcas históricas do passado, podendo perceber esta afirmativa nas falas representadas na tabela 2 .

Tabela 2 - Relevância dos estudos culturais para os entrevistados

Entrevistados (as)

Relevância/Justificativa

8a A - Entrevistado (a)

“Como já diz, é uma cultura popular, está ao nosso redor, devemos estudar para saber o que nos rodeiam para saber o que, de fato, faz parte das nossas vidas".

8ㅁ B - Entrevistado (a)

“A cultura popular é importante para que nós possamos aprender mais das coisas que a população faz, fala e etc...". 
8a C - Entrevistado (a)

9a A - Entrevistado (a)

9a B - Entrevistado (a)
"É importante saber da cultura do nosso povo, aprender e passar adiante".

"É importante para jovens e adolescentes saber a cultura de seu país, estado e cidade".

"É importante para que as pessoas entendam que todos têm a sua cultura e que ninguém tem que ter preconceito com isso".

Fonte: Tabela criada para fins da pesquisa (2019).

Desse modo, os benefícios advindos da estratégia de "ensino e cultura popular" na escola em que os entrevistados foram abordados aparecem de forma clara e reflete na sua condição de indivíduo enquanto membro de uma sociedade altamente diversificada. Além do mais, as respostas concedidas pelos participantes evidenciam uma preocupação referente à necessidade de se trabalhar com cultura popular para que possam se reconhecer socialmente, visto que compreendem que a cultura popular nada mais é que o artifício mais rico e eficiente de descobertas, conservação e conquistas históricas.

Os estudos da cultura, por sua vez, são caracterizados pela interdisciplinaridade própria de sua natureza, isto é, a transitividade dos conteúdos desenvolvidos no contexto cultural. Nessa ótica, é válido salientar que a subjetividade do termo "cultura popular" implica significativamente no modo de compreensão dos alunos entrevistados, uma vez que embora exista equivalência nos discursos, todas as opiniões são formadas por princípios diferentes, mas, que não deturpam a significação epistemológica.

Os entrevistados compreendem a essência das culturas populares a ponto de definir critérios que marcam a singularidade cultural de cada grupo social, isto é, os discentes pontuam claramente a necessidade de marcar a pluralidade em "culturas populares", pois entendem que a cultura de um povo é constituída por costumes históricos perpassados em gerações. Portanto, se uma sociedade é composta por vários grupos sociais, nada mais lógico que evocar "culturas populares", pois não se trata apenas de uma unidade cultural.

Veremos então que as falas apresentadas na tabela 2 denunciam a capacidade existente nos entrevistados, de discutir profundamente sobre cultura popular nos mais diversos contextos, capacidade esta que fora desenvolvida, potencialmente, pelos projetos desenvolvidos pela instituição de ensino em que são matriculados. Desse modo, a profundidade nos discursos aqui pauta- 
dos pode ser percebida quando estes alunos se atentem a variação cultural, isto é, aos costumes culturais que podem estar condicionados a fatores determinantes como cidade, estado e país. Pode-se ressaltar, também, que estes indivíduos ao discorrem sobre a relevância dos estudos referentes à cultura popular preocupam-se e reconhecem que estes estudos são necessários para que não se deixem perder na contemporaneidade as memórias coletivas do passado que, consequentemente, evoluíram-se de modo a serem concebidas como patrimônio e/ou identidade cultural de um povo.

Desse modo, é imprescindível considerar a relação intrínseca que existem entre cultura popular em consonância com conteúdo didáticos e paradidáticos trabalhados em sala de aula. Considera-se, ainda, que muitas são as formas de se abordar cultura popular no âmbito escolar, independentemente do seguimento ou ano. A fotografia, por exemplo, não é um recurso atual da sociedade, porém, pode ser utilizada de forma direta e lúdica. No ensino de história, com mais ênfase, a fotografia assume um papel essencial no processo de assimilação do conhecimento, pois despertam a atenção do indivíduo leitor, não somente nessa disciplina, como também em outras.

Sobre esta perspectiva, Priori (2008, p. 93) enfatiza que "do ponto de vista das Ciências Humanas, a fotografia, em suas diferentes formas, pode fornecer informações importantes sobre fatos históricos, e mais amplamente, ajuda a compreensão da evolução da sociedade". Sendo assim, o uso das fotografias em sala de aula pode ser um grande aliado à construção do saber, pois instiga o indivíduo a pensar para além do que a imagem retrata quanto proposto este desafio, além de despertar o interesse em conhecer fatos do passado que reflete na condição de vida atual e também ajuda entender as lacunas históricas que foram deturpadas durante estudos realizados, assumindo a posição de objeto de memória.

Com o avanço tecnológico os métodos didáticos no ofício da função da docência têm sido muito ameaçados, tendo em vista que muitos profissionais da educação se mostram resistentes ao progresso da tecnologia, atitude essa que influencia diretamente na qualidade da educação proporcionada na atual conjuntura das escolas públicas. Não somente o quadro técnico de funcionários foi afetado por esta modificação tecnológica, pois muitos dos alunos assumiram maior interesse pelos prazeres que a inovação proporciona, como o bombardeamento de informações já produzidas, pois não precisarão pensar sobre e/ ou serem seus próprios formadores de suas opiniões e pensamentos críticos.

Dessa forma, é visível a mudança de comportamento que ocorre com os alunos da contemporaneidade, revelando a necessidade de se trabalhar 
com propostas atrativas e que estejam em conformidade com o interesse coletivo do público, como exemplo, eventos festivos culturais. Nessa perspectiva, Murray $(2008$, p. 97) asseveram que "no país da ginga, do drible de corpo, do molejo do samba, dos passos codificados do terreiro e da malícia do golpe de capoeira, podemos afirmar que as nossas festas populares são o símbolo máximo da nossa identidade nacional e espelho coreógrafo da alma do povo".

Assim, compreende-se que as festas populares fazem parte de um conjunto cultural que representa de certa forma o manifesto de um povo. Entender o que são festas populares e sua contribuição na formação do indivíduo é, antes de tudo, por este ser como parte integral do que reverencia nos eventos populares; é semear a construção do conhecimento por meio da cultura e da imersão social, pois esta prática desperta a sensibilidade do aluno em relação aos seus antepassados, bem como marcas do presente postas à sociedade contemporânea.

\section{Considerações finais}

As pesquisas realizadas durante a tessitura deste trabalho permitem concluir que ensinar por meio da cultura popular e, por conseguinte, pô-la como artifício sólido para construção do saber é possível, relevante e plausível, pois ao tratar-se de cultura envolve, automaticamente, questões voltadas ao passado de um povo que reflete diretamente no modo de vida atual de um grupo social.

Ademais, esta iniciativa desperta memórias coletivas e individuais, o que faz o aluno sentir-se como parte integrante de uma comunidade e também desenvolvem capacidades cognitivas de discorrer de forma crítica sobre a defesa e conservação do patrimônio material e imaterial de uma nação. Assim, enfatiza-se o papel fundamental que assumem as escolas e os professores em geral ao relembrar, constantemente, os princípios do relativismo cultural para as gerações modernistas, que além de ensinar auxiliam os indivíduos que compõem este espaço a entender e discutir as diversidades culturais, além dos valores como respeito e tolerância.

Além do mais, nota-se que no ambiente escolar acontecem frequentemente situações em que a integridade moral e física dos alunos é colocada em condição de risco, em virtude da falta de tolerância aos costumes sociais entre os discentes, que é decorrente da falta de conhecimento. Sendo assim, as instituições de ensino devem atentar-se ainda mais a desenvolver projetos e atividades que proporcione a oportunidade de conhecer o, até então, dife- 
rente para o aluno. Nesse sentido, observamos que os alunos entrevistados, pelas experiências que foram submetidos nos eventos culturais promovidos pela instituição em que estudam, possuem discernimento e sensibilidade de reconhecer os vastos costumes culturais que os povos brasileiros detêm, assim, evidenciando a necessidade dos estudos culturais estarem em consonância com os ensinamentos perpassados na escola.

A percepção de pluralidade cultural é perceptível nos discursos dos alunos que participaram dessa pesquisa, tais que demonstram ciência de que ao se tratar de cultura popular, abarcam, consequentemente, diversos grupos sociais que também compactuam com as atividades que foram historicamente conservadas e, então, concebidas como patrimônio e identidade cultural. As falas apresentadas revelam, ainda, uma preocupação considerável quanto à preservação dos bens culturais, pois reconhecem que é necessário estudar cultura popular para que não se perca nas alegorias da contemporaneidade as identidades culturais locais, regionais e nacionais.

Desse modo, a cultura popular pode ser concebida como um importante processo para a construção do conhecimento humano, visto que por meio dela pode-se ensinar não somente os costumes dos povos de uma nação, mas, também, faculdades como respeito, tolerância, dignidade e conteúdos programáticos de numerosas disciplinas.

\section{Referências}

AZEVEDO, R. Cultura popular, literatura e padrões culturais. 2008. Disponível em: <http://www.ricardoazevedo.com.br/wp/wp-content/uploads/Cultura-popular.pdf>. Acesso em: 23 fev. 2019.

BRASIL. Ministério de Educação e Cultura. LDB - Lei no 9394/96, de 20 de dezembro de 1996. Estabelece as diretrizes e bases da Educação Nacional. Brasília: MEC, 1996.

BRUNER, J. O Processo da educação Geral. 2a ed. São Paulo: Nacional, 1991.

COELHO, L.; PISONI, S. Revista e-Ped - FACOS/CNEC Osório Vol.2 - №1 AGO/2012 - ISSN2237-7077 144 Vygotsky: sua teoria e a influência na educação. Revista E-ped, Osório, v. 2, n. 1, p.144-152, 13 ago. 2012. Trimensal. Disponível em: <http://www.facos.edu.br/publicacoes/revistas/e-ped/agosto_2012/\#/page/149>. Acesso em: 13 nov. 2019. 
CRUZ, J. Processo de ensino-aprendizagem na sociedade da informação. Educ. Soc., Campinas, v. 29, n. 105, p. 1023-1042, Dec. 2008. Available from <http://www.scielo.br/scielo.php?script=sci_arttext\&pid=S0101 73302008000400005\&Ing=en\&nrm=iso>. Acesso em: 13 nov. 2019. http:// dx.doi.org/10.1590/S0101-73302008000400005.

DOMINGUES, P. Cultura popular: as construções de um conceito na produção historiográfica. História, Franca, v. 30, n. 2, p. 401-419, Dec. 2011. Available from <http://www.scielo.br/scielo.php?script=sci_arttext\&pid=S0101-90742011000200019\&Ing=en\&nrm=iso >.access on $1 \overline{9}$ Nov. 2019. http://dx.doi.org/10.1590/S0101-90742011000200019.

FREIRE, P. Pedagogia da Autonomia: saberes necessários à prática educativa. São Paulo: Paz e Terra, 1996.

GERHARDT, T.; SILVEIRA, D. (org.). Métodos de Pesquisa. Porto Alegre: Editora da UFRGS, 2009.

GOLDEMBERG, J. O repensar da educação no Brasil. Estud. av. São Paulo, v. 7, n. 18, p. 65-137, agosto de 1993. Disponível em <http://www.scielo.br/scielo.php?script=sci_arttext \&pid=S0103=40141993000200004-\&lng=en \&nrmiso>. Acesso em 16 dez. 2019. http://dx.doi.org/10.1590/s010340141993000200004.

LARAIA, R. B. Cultura: um conceito antropológico. Zahar. Rio de Janeiro, 1986.

MURRAY, C. (2008). As festas populares objeto de memória. In SILVA, R.(Org.). Cultura popular e educação: Salto para o futuro.1a ed. Brasília; cap. II. p. 95123.

OLIVEIRA, M. et al. As contribuições da teoria piagetiana para o processo de ensino- aprendizagem. Campina Grande: Realize, 2012. 09 p. Disponível em: <http://www.editorarealize.com.br/revistas/ebook_fiped/trabalhos/ebook_ fiped4.pdf>. Acesso em: 13 nov. 2019.

PIAGET, J. Psicologia da inteligência. Rio de Janeiro: Zahar, 1977.

PLATÃO. Teeteto - Crátilo. In: Diálogos de Platão. Tradução por Carlos Alberto Nunes. 3a.ed., Belém: Universidade Federal do Pará, 2001, p. 83.

PRIORI, M. (2008) A fotografia como objeto de memória. In SILVA, R. (Org.). Cultura popular e educação: Salto para o futuro.1à ed. Brasília; cap. II. p. 8394. 
RIBEIRO, P. Cultura popular: as construções de um conceito na produção historiográfica. História, Franca, v. 30, n. 2, p. 401-419, Dec. 2009. Available from <http://www.scielo.br/scielo.php?script=sci_arttext\&pid=S0101-90742011000200019\&Ing=en\&nrm=iso>.access on 24 Nov. 2019. http://dx.doi.org/10.1590/S0101-90742011000200019.

SILVA, R. (Org.). Cultura popular e educação: Salto para o futuro. 1a ed. Brasília; 2008.

TURNER, J. H. Sociologia Conceitos e Aplicações. 1eed. São Paulo: Ed Markon, 2018.

VIGOTSKY, L. S. Psicologia pedagógica. Porto Alegre: Artmed, 2003.

WERNECK, V. Sobre o processo de construção do conhecimento: o papel do ensino e da pesquisa. Ensaio: Avaliação e Políticas Públicas em Educação, [s.l.], v. 14, n. 51, p.173-196, jun. 2006. FapUNIFESP (SciELO). http://dx.doi. org/10.1590/s0104-40362006000200003.

Data de recebimento: 05.06.2020

Data de aceite: 11.06.2021 